\title{
Genetic diversity assessment of Aconitum coreanum (H. Lév.) Rapaics (Ranunculaceae), an endangered plant species in Korea, using microsatellite markers
}

\author{
Hyosig Won ${ }^{1, *}$, Young-Eun Yun ${ }^{2}$, Myounghai Kwak ${ }^{2}$ and Jeong Eun $\mathrm{Han}^{2}$ \\ ${ }^{1}$ Department of Biological Sciences, Daegu University, Gyeongsan 712-714, Korea \\ ${ }^{2}$ National Institute of Biological Resources, Incheon 404-708, Korea \\ *Correspondent:wonhs@daegu.ac.kr
}

\begin{abstract}
To assess the genetic diversity of Aconitum coreanum (Ranunculaceae) populations in Korea, we have amplified and sequenced eight organellar marker regions, and developed and analyzed microsatellite markers. No sequence variation was detected from the eight organellar markers. Ten microsatellites were developed using Next Generation Sequencing and two microsatellite markers, AK_CA03 and AK_CT07, were identified polymorphic and applied for 143 individuals of twelve A. coreanum populations. Four and five alleles were detected for the two microsatellite loci, respectively, and number of migrants $\left(N_{m}\right)$ was estimated as 1.12586. Two microsatellite marker loci showed $F_{S T}$ of 0.205 and 0.275 , respectively. The heterozygosity deficit, low level of among-population differentiation, small size of gene flow, and lack of sequence variation of the organellar markers suggest that A. coreanum is reproductively isolated from other Aconitum species and there has been continuous gene flow among the populations of A. coreanum or it has dispersed relatively recently after speciation. Though population pairwise $F_{S T}$ 's presented significant geographic structure, further sampling and study will be necessary to confirm this.
\end{abstract}

Keywords: Aconitum coreanum, conservation, genetic diversity, microsatellite, organellar marker

\section{INTRODUCTION}

Aconitum coreanum (H. Lév.) Rapaics is a perennial herbaceous plant distributed in Korea, northern China, Far East Russia, and Mongolia (Li and Kadota, 2001; Park, 2007) and a member of Aconitum subg. Aconitum according to Kadota (1987). Aconitum coreanum has been utilized as a traditional medicinal plant in Eastern Asia, and has been widely studied for its useful chemical components and effects (Bessonova et al., 1987; Dzhakhangirov and Bessonova, 2002; Liang et al., 2012; Tang et al., 2012). Due to over-exploitation for traditional medicinal use, populations and number of individuals have been rapidly decreasing in Korea. Thus, $A$. coreanum has been designated and protected as Level II Endangered Wild Plants by the Ministry of Environment, Republic of Korea.

Aconitum coreanum is easily distinguished from other Aconitum species distributed in Korea by its erect habit, deeply and finely incised leaf lobes linear to lanceolate, pubescent pedicels with curved hairs, terminal 2-7-flowered inflorescence, yellowish sepals, and 3 carpels (Park, 2007). Collection history indicates that A. corea- num was once distributed widely from central to northern part of Korea (Korea Biodiversity Information System; http://nature.go.kr; Lee et al., 2005), but the distribution range has been reduced and found mainly in Gangwon and northern Chungbuk area at the present time (Lee et al., 2005). Lim (2003), Noh and Park (2000), and Noh (2009) presented the phylogenetic position of A. coreanum as basal of the Aconitum subg. Aconitum, distinct from the rest of the group from the molecular phylogenetic analyses of nuclear ribosomal internal transcribed spacer (nrITS) sequences, xanthine dehydrogenase gene (XDH) sequences, and chloroplast $p s b A-t r n H, r b c L-a c c D$, and trnL-trnF IGS region sequences. Also, Noh (2009) discovered that there is only one nrITS sequence type and $\mathrm{XDH}$ gene sequence type detected from A. coreanum, contrary to the multiple sequence types detected from other tetraploid Aconitum species putatively originated by hybridization. Chromosome number of $A$. coreanum has also been reported as tetraploid $(2 \mathrm{n}=32$; Lee 1967; Chung et al., 2011; but, see Jin et al., 1998 for $2 \mathrm{n}=24+$ $1 \mathrm{~B})$. These suggest that $A$. coreanum is a distinct and reproductively isolated tetraploid species from other Aconitum species in Korea.

Although A. coreanum has been designated as an en- 
dangered species, there has been little study on its distribution, ecology, demography, reproduction, pollination mechanism, seed dispersal, and population dynamics. Generally, Aconitum species are known to undergo both sexual and vegetative reproduction (Kadota, 1987; Oh and Park, 1998; Bosch and Waser, 1999; Chung and Park, 2000). Although the flowers of Aconitum are bisexual, protandry is common and bumble bees (Bombus Latreille) are known as major pollinators. Matured seeds are known to fall down gravitationally near the mother plant, and no other dispersal mechanisms are reported. Vegetatively, new lateral roots are formed every year, replacing previous year's root. In planning conservation strategy and scheme for an endangered species, understanding its genetic structure and variation is also a key factor. Thus as a first step to establish a conservation plan for A. coreanum, we have here developed and applied microsatellite markers, which is a very powerful tool in conservation biology in assessing genetic variation and population structure, to A. coreanum populations, in addition to organellar genome region sequence variation analyses.

Microsatellites are composed of tandem repeated 1-6 base pair nucleotide motifs, referred to as short tandem repeats (STRs), simple sequence repeats (SSRs), simple sequence length polymorphisms (SSLPs) or sequence tagged sites (STS) (Hamilton et al., 1999; Kalia et al., 2011). Among these molecular markers, microsatellites are codominant, highly polymorphic and have better reproducibility. Thus, microsatellites are preferred for genetic diversity study within species or/and elucidating demographic history of populations (Gupta et al., 1996; Zeng et al., 2004; Tehrani et al., 2009). However, the development of microsatellite through traditional method is timeconsuming and labor-intensive, thus has been keeping researchers from developing and applying microsatellites contrary to its benefits. Recently, microsatellite marker design using the next generation sequencing (NGS) has become popular and cost-effective.

Here we developed microsatellite markers for A. cor- eanum using NGS and applied them to analyze the genetic diversity of A. coreanum populations in Korea, though which we tried to understand its genetic structure and variation.

\section{Materials And Methods}

\section{Sampling and DNA extraction}

Due to lack of survey information and reduction in distribution area and number of individuals, we limited collection sites to Gangwon area where recent reports on population size and distribution information were available (Y.-C. Kim, pers. comm.). Individuals of A. coreanum were randomly and sparsely distributed over the mountain slope and at least couple of meters apart from each other, in general. Thus, we had to survey at least 50 $\times 50 \mathrm{~m}$ area per site to find enough number of individuals, and all the individuals spotted were sampled. Samples were collected from June to October 2011. One fresh leaf was collected from each individual of $12 \mathrm{~A}$. coreanum populations for the study (Table 1). DNA was extracted directly from the fresh leaf or from silica-gel dried leaf. DNeasy Plant mini kit (QIAGEN) was used to extract DNA. Extracted DNA was checked for its concentration using $1 \%$ agarose gel electrophoresis and further quantified using Optizen 3220 UV bio nanoliter cell (Mecasys Co., Ltd.).

\section{Amplification and sequencing of organellar markers}

Eight organellar markers, chloroplast $y c f 3$ intron, $y c f 4$ psaI IGS, $r b c L-a c c D$ IGS, trnT-trnL IGS, trnL intron, trnL-trnF IGS, atpF-atpH IGS, and mitochondrial nadl exon b-c intron regions, were PCR-amplified and sequenced to check any genetic variation among the individuals of A. coreanum. Chloroplast $p s b K-p s b I$ IGS and $p s b A-$ $\operatorname{trnH}$ IGS regions were also included in the initial tests, but discarded due to PCR-amplification or sequencing

Table 1. List of Aconitum coreanum populations and number of individuals sampled for genetic diversity assessment.

\begin{tabular}{lcl}
\hline \multicolumn{1}{c}{ Popn. } & \#individuals sampled & \multicolumn{1}{c}{ Location } \\
\hline Seondol & 23 & Korea. Gangwon, Youngwol, Youngwol-eup, Bangjeol-ri \\
Donggang & 14 & Korea. Gangwon, Youngwol, Youngwol-eup, Munsan-ri \\
Hanbando & 16 & Korea. Gangwon, Youngwol, Seo-myeon, Sincheon, Ongjeong \\
Baeilchi & 4 & Korea. Gangwon, Youngwol, Buk-myeon, Gwangdeok-ri \\
Tongduduk & 5 & Korea. Gangwon, Youngwol, Seo-myeon, Gwangjeon-ri \\
Panun & 15 & Korea. Gangwon, Youngwol, Jucheon-myeon, Panun-ri \\
Gundungchi & 19 & Korea. Gangwon, Youngwol, Jucheon-myeon-Seo-myeon \\
Daehwa & 14 & Korea. Gangwon, Pyeongchang, Daehwa-myeon, Ha-anmiri \\
Wondongjae & 8 & Korea. Gangwon, Pyeongchang, Pyeongchang-eup, Majiri \\
Hongcheon & 7 & Korea. Gangwon, Hongcheon, Bukbang-myeon, Busanwon-ri \\
Daeryongsan & 8 & Korea. Gangwon, Chuncheon, Dong-myeon, Pyeongchon-ri \\
Hau & 10 & Korea. Gangwon, Chuncheon, Buksan-myeon, Cheongpyeong-ri \\
\hline \multicolumn{1}{c}{ Total } & 143 & \\
\hline
\end{tabular}


failure. We amplified and sequenced the markers using primer sets developed by Taberlet et al. (1991), Demesure et al. (1995), Fazekas et al. (2008), and J. Lee (pers. comm.; Green Plant Research Institute, Suwon, Korea) and followed the PCR and sequencing protocols of Won and Renner (2005) and Won (2009). The resulting sequence chromatograms were verified and checked with Sequencher program (ver. 4.9; Genecodes), and their lengths and $\mathrm{G}+\mathrm{C}$ contents were checked with PAUP* $4.0 \mathrm{~b} 10$ (Swofford, 2002) after building data matrices.

\section{Development of Microsatellite markers}

Three A. coreanum DNA samples collected from Seondol, Donggang, and Baeilchi populations were used to develop microsatellite markers. Microsatellite discovery were performed as previously described (Yu et al., 2011). DNA from one individual was subjected to sequencing using a 1/4 plate of a Roche 454 GS-FLX titanium platform at NICEM(Seoul, Korea). The reads were assembled by Newbler version 2.6 (Roche Diagnostics, 454 Life Science). All perfect di- and tri-nucleotide repeats were searched against the assembled contigs and single read using the 'ssr_finder.pl' perl program (Shanker et al., 2007). The primers to amplify discovered repeats were designed using Primer3 software package (http://wwwgenome.wi.mit.edu/cgi-bin/primer/primer3_www.cgi) (Rozen and Skaletsky, 1998), setting with 22 bp optimal primer size (range $18-26 \mathrm{bp}), 58^{\circ} \mathrm{C}$ optimal annealing temperature (range $55-62^{\circ} \mathrm{C}$ ).

To genotype microsatellites, a $5^{\prime}$-M13 tail was added to each forward primer to allow fluorescent labeling during amplification (Schuelke, 2000). PCR mixture included 10 ng genomic DNA, 0.5 unit Ex-Taq polymerase (TaKaRa, Japan), $1 \times$ Ex-Taq buffer, dNTP mixture (2.5 $\mathrm{mM}$ each), 4 pmol forward primer, 16 pmol reverse primer, 16 pmol fluorescent labeled M13(-21) primer (6FAM, NED, PET and VIC). We followed the PCR protocols of Schuelke (2000) and amplified PCR products were checked by $2 \%$ agarose gel electrophoresis with known DNA size marker. Then, GeneScan ${ }^{\mathrm{TM}}$ 500LIZ size standard and $\mathrm{HiDi}^{\mathrm{TM}}$ formamide (Applied Biosystems, USA) were added to the PCR products and run on ABI 3730XL (Applied Biosystems, USA) at NICEM for fragment size detection. Genotypes were detected by GeneMarker ${ }^{\circledR}$ program (version 1.85; Softgenetics LLC).

To check whether the microsatellite primer sets properly amplified the designated microsatellite loci, PCR-amplification and sequencing were done with the primer sets without adding fluorescent-labeled primer, applying the same PCR cycles and sequencing protocols. Sequencing products were run on ABI 3730XL (Applied Biosystems, USA) at NICEM, and sequence and fragment sizes were verified with Sequencher program (ver. 5.01 Genecodes).
Table 2. Results of the organellar marker amplification/sequencing of Aconitum coreanum. One individual each from ten populations was amplified and sequenced for these markers.

\begin{tabular}{lccc}
\hline \multicolumn{1}{c}{ Marker } & $\begin{array}{c}\text { Amplified/sequenced } \\
\text { length }(\mathrm{bp})\end{array}$ & $\begin{array}{c}\mathrm{G}+\mathrm{C} \\
\text { content }(\%)\end{array}$ & $\begin{array}{c}\text { Variation } \\
\text { observed }\end{array}$ \\
\hline chloroplast & & & \\
ycf3 intron & $\sim 550$ & 28.2 & None \\
ycf4-psaI IGS & $\sim 490$ & 25.4 & None \\
rbcL-accD IGS & $\sim 780$ & 37.1 & None \\
trnT-trnL IGS & $\sim 670$ & 28.5 & None \\
trnL intron & $\sim 480$ & 31.9 & None \\
trnL-trnF IGS & $\sim 440$ & 33.1 & None \\
$\begin{array}{l}\text { atpF-atpH IGS } \\
\text { mitochondrion }\end{array}$ & $\sim 530$ & 34.2 & None \\
$\begin{array}{l}\text { nadl b-c intron } \\
\text { (partial) }\end{array}$ & $\sim 580$ & & \\
\hline
\end{tabular}

\section{Analysis of genetic diversity using microsatellite markers}

Two microsatellite loci, AK-CA03 and AK-CT07, were amplified and genotyped for all the A. coreanum samples obtained to analyze their genetic diversity, following the protocols explained previously. Amplified microsatellite fragments were sent to Biomedic Ltd. (Bucheon, Gyeonggi, Korea) for genotyping. Fragment size data were converted into input data file using Convert program (Glaubitz, 2004). Using GENEPOP (v 3.1d; Raymond and Rousset, 1995) and FSTAT (v 2.9.3.2; Goudet, 2001), we estimated the proportion of polymorphic loci and the average number of alleles per locus, $F_{I S}$ (inbreeding coefficient of an individual (I), relative to the subpopulation (S)) and $F_{S T}$ (the effect of subpopulations (S) compared to the total population (T)), and $F_{I T}$. The observed and expected heterozygosity $\left(H_{O}\right.$ and $\left.H_{E}\right)$, population pairwise $F_{S T}$ 's, AMOVA (analysis of molecular variance) test, and HardyWeinberg equilibrium (HWE) test using Markov Chain were done with Arlequin (ver. 3.5; Excoffier et al., 2005). The MICROCHECKER program (Van Oosterhout et al., 2004) was used to check for null alleles and scoring errors due to stuttering or large allele drop-out.

\section{Results}

\section{Organellar marker sequence}

The amplified length and $\mathrm{G}+\mathrm{C}$ contents of the eight organellar markers amplified for the individuals of $10 \mathrm{~A}$. coreanum populations are presented in Table 2 . No sequence variation was detected. Chloroplast $r b c L$-accD IGS region was longest of all the markers amplified and $\mathrm{mt}$ nadl exon b-c intron showed distinctively high $\mathrm{G}+\mathrm{C}$ contents compared to those of the chloroplast markers. BLAST search of the eight marker sequences of $A$. coreanum confirmed that those sequences show highest se- 
Table 3. Total occurrence of repeats in Aconitum coreanum genomes.

\begin{tabular}{|c|c|c|c|c|c|c|c|c|c|c|c|c|c|c|c|c|c|c|c|}
\hline & \multicolumn{19}{|c|}{ No. of repeat count } \\
\hline & 4 & 5 & 6 & 7 & 8 & 9 & 10 & 11 & 12 & 13 & 14 & 15 & 16 & 17 & 18 & 19 & 20 & 21 & Total \\
\hline \multicolumn{20}{|l|}{ Di-nucleotide } \\
\hline AT/TA & 1919 & 243 & 35 & 15 & 4 & 9 & 5 & 4 & - & 1 & - & 1 & - & - & - & - & - & - & 2236 \\
\hline $\mathrm{CA} / \mathrm{AC} / \mathrm{GT} / \mathrm{TG}$ & 1476 & 181 & 40 & 19 & 8 & 5 & 1 & 1 & - & - & - & - & - & - & - & - & - & - & 1731 \\
\hline CT/TC/GA/AG & 1913 & 236 & 72 & 36 & 16 & 6 & 3 & 1 & 1 & - & - & - & - & - & - & - & - & - & 2284 \\
\hline GC/CG & 89 & 8 & 1 & - & - & - & - & 1 & - & - & - & - & - & - & - & - & - & - & 99 \\
\hline \multicolumn{20}{|l|}{ Tri-nucleotide } \\
\hline AAT/ATA/TAA/TTA/TAT/ATT & 194 & 34 & 11 & 5 & 1 & 2 & - & - & - & - & - & - & - & - & - & - & - & 1 & 248 \\
\hline AAC/ACA/CAA/GTT/TGT/TTG & 228 & 56 & 18 & 8 & 2 & - & 1 & - & - & - & 1 & - & - & - & - & - & - & - & 314 \\
\hline AAG/AGA/GAA/CTT/TCT/TTC & 479 & 68 & 19 & 4 & 5 & - & - & - & - & - & - & - & - & - & - & - & - & - & 575 \\
\hline ATG/TGA/GAT/CAT/ATC/TCA & 151 & 46 & 4 & 2 & - & - & - & - & - & - & - & - & - & - & - & - & - & - & 203 \\
\hline ACC/CAC/CCA/GGT/GTG/TGG & 163 & 42 & 10 & 3 & - & - & - & - & - & - & - & - & - & - & - & - & - & - & 218 \\
\hline ACG/CGA/GAC/CGT/GTC/TCG & 16 & - & - & - & - & - & - & - & - & - & - & - & - & - & - & - & - & - & 16 \\
\hline AGT/GTA/TAG/ACT/CTA/TAC & 35 & - & - & - & - & - & - & - & - & - & - & - & - & - & - & - & - & - & 35 \\
\hline AGC/GCA/CAG/GCT/CTG/TGC & 54 & 18 & 2 & 2 & - & - & - & 1 & - & - & - & - & - & - & - & - & - & - & 77 \\
\hline AGG/GAG/GGA/CCT/TCT/TCC & 120 & 29 & 20 & 4 & 4 & 2 & 1 & 2 & - & - & - & - & - & - & - & - & - & - & 182 \\
\hline $\mathrm{CCG} / \mathrm{CGC} / \mathrm{GCC} / \mathrm{CGG} / \mathrm{GCG} / \mathrm{GGC}$ & 6 & 3 & - & - & - & - & - & - & - & - & - & - & - & - & - & - & - & - & 9 \\
\hline AAA & 1 & - & - & - & - & - & - & - & - & - & - & - & - & - & - & - & - & - & 1 \\
\hline
\end{tabular}

Table 4. Primer sequence and characteristics of 10 microsatellite loci in Aconitum coreanum.

\begin{tabular}{|c|c|c|c|c|c|c|c|}
\hline Locus & Repeat motif & Primer sequence $\left(5^{\prime}-3^{\prime}\right)$ & $\operatorname{Tm}\left({ }^{\circ} \mathrm{C}\right)$ & Size range (bp) & $\mathrm{Na}$ & $H_{O}$ & $H_{E}$ \\
\hline AK_AT03 & $\mathrm{AT}_{(10)}$ & $\begin{array}{l}\text { F:ACGATTCCGTCGTATAACAATC } \\
\text { R:GGAATTAGTTCCTGAGTCCCTT }\end{array}$ & 56 & 267 & 1 & - & - \\
\hline AK_AT08 & $\mathrm{AT}_{(6)}$ & $\begin{array}{l}\text { F:CATCTCTCCGAAAGACAATCTC } \\
\text { R:TTTATTTTTATTCGGACATGGG }\end{array}$ & 56 & 240 & 1 & - & - \\
\hline AK_AT13 & $\mathrm{AT}_{(6)}$ & $\begin{array}{l}\text { F:GCAGAAACCAATACTGACCACT } \\
\text { R:GGAATTACCCAAGAGATGTCAA }\end{array}$ & 56 & 224 & 1 & - & - \\
\hline AK_AT14 & $\mathrm{AT}_{(6)}$ & $\begin{array}{l}\text { F:ACGATTCCGAAGTATGACAATC } \\
\text { R:ATCCCTTTTGAAGTGGGTTAAT }\end{array}$ & 56 & 218 & 1 & - & - \\
\hline AK_AT20 & $\mathrm{AT}_{(6)}$ & $\begin{array}{l}\text { F:GACCCAAAAGTGACTCAAAAAG } \\
\text { R:ACCACACTCTAACCGTATGTCC }\end{array}$ & 56 & 241 & 1 & - & - \\
\hline AK_CT07 & $\mathrm{CT}_{(7)}$ & $\begin{array}{l}\text { F:TTCATATTGATCAAGTCCACCA } \\
\text { R:TCAGCAGGTTCTGTCCTTATTT }\end{array}$ & 56 & $169-177$ & 4 & 0.20 & $0.64 * *$ \\
\hline AK_CT14 & $\mathrm{CT}_{(6)}$ & $\begin{array}{l}\text { F:CAAATGATAGTTAGATCAAAAG TACG } \\
\text { R:AAATTTTAAGGTTTCGGGTCT }\end{array}$ & 56 & 176 & 1 & - & - \\
\hline AK_CT16 & $\mathrm{CT}_{(6)}$ & $\begin{array}{l}\text { F:GTTATAAATTGTGGATCGCCAG } \\
\text { R:CAAAGATACCTTCCAAGTGGC }\end{array}$ & 56 & 224 & 1 & - & - \\
\hline AK_CT18 & $\mathrm{CT}_{(6)}$ & $\begin{array}{l}\text { F:TTTGTTATAATTGTGGATCGCC } \\
\text { R:CAAAGATACCTTCCAAGTGGC }\end{array}$ & 56 & 226 & 1 & - & - \\
\hline AK_CA03 & $\mathrm{CA}_{(7)}$ & $\begin{array}{l}\text { F:AATAAGCAATGTTGGTTGGAAG } \\
\text { R:TTGAGTACCACTTGGTCGAAAT }\end{array}$ & 56 & $238-242$ & 3 & 0.33 & $0.58^{*}$ \\
\hline
\end{tabular}

Significant Hardy-Weinberg Equilibrium $(H W E)$ departures for each locus was determined by adding $*=P<0.05, * *=P<0.01-$; monomorphic data

quence similarities with other Aconitum sequences already on GenBank (data not shown).

\section{Microsatellite marker development and assessment}

We obtained 265,470 reads $(87.99 \mathrm{Mb})$ from $1 / 4$ plate run using 454 GS-FLX titanium. The identified di- and tri- repeats were shown in Table 3 . The most frequent di-nucleotide type found from $A$. coreanum genome se- quences was CT (35.97\%), followed by AT (35.21\%), CA repeats $(27.26 \%)$, and $\mathrm{GC}(1.56 \%)$. The AT repeats among di-nucleotide repeats were the longest with 15 repeats (30 bp), the AAT among tri-nucleotide repeats with 21 repeats (63 bp). From higher copy numbers, 48 microsatellite primer sets were examined for amplification. Ten microsatellites $(20.83 \%$ ) were successfully amplified and were tested for polymorphism further with 15 randomly chosen individuals from three populations. Among 10 
Table 5. Microsatellite allele frequencies detected from the Aconitum coreanum populations in Korea.

\begin{tabular}{|c|c|c|c|c|c|c|c|c|c|c|c|}
\hline \multirow{2}{*}{ Popn. } & \multicolumn{5}{|c|}{ AK_CA03 } & \multicolumn{6}{|c|}{ AK_CT07 } \\
\hline & $\mathrm{N}$ & 235 & 237 & 239 & 241 & $\mathrm{~N}$ & 170 & 172 & 174 & 178 & 180 \\
\hline Seondol & 23 & 0.109 & 0.630 & 0.261 & 0 & 23 & 0.304 & 0.587 & 0.043 & 0 & 0.065 \\
\hline Donggang & 14 & 0.464 & 0.143 & 0.393 & 0 & 11 & 0.364 & 0.136 & 0.318 & 0.182 & 0 \\
\hline Hanbando & 16 & 0.156 & 0.594 & 0.250 & 0 & 16 & 0.531 & 0.250 & 0.219 & 0 & 0 \\
\hline Baeilchi & 4 & 0 & 1.000 & 0 & 0 & 3 & 0 & 1.000 & 0 & 0 & 0 \\
\hline Tongduduk & 5 & 0.100 & 0.900 & 0 & 0 & 5 & 0.100 & 0.800 & 0.100 & 0 & 0 \\
\hline Panun & 15 & 0.033 & 0.767 & 0.200 & 0 & 15 & 0.233 & 0.767 & 0 & 0 & 0 \\
\hline Gundungchi & 19 & 0.105 & 0.605 & 0.289 & 0 & 15 & 0.033 & 0.567 & 0.400 & 0 & 0 \\
\hline Daehwa & 14 & 0.107 & 0.857 & 0.036 & 0 & 12 & 0.167 & 0.250 & 0.583 & 0 & 0 \\
\hline Wondongjae & 7 & 0.286 & 0.286 & 0.429 & 0 & 7 & 0.143 & 0.286 & 0.571 & 0 & 0 \\
\hline Hongcheon & 7 & 0 & 0.714 & 0.286 & 0 & 7 & 0.214 & 0.329 & 0.357 & 0 & 0 \\
\hline Daeryongsan & 8 & 0 & 0.062 & 0.938 & 0 & 8 & 0 & 1.000 & 0 & 0 & 0 \\
\hline $\mathrm{Hau}$ & 10 & 0 & 0 & 0.950 & 0.050 & 10 & 0 & 0.950 & 0.050 & 0 & 0 \\
\hline Total & 142 & 0.127 & 0.547 & 0.336 & 0.004 & 132 & 0.216 & 0.542 & 0.216 & 0.015 & 0.011 \\
\hline
\end{tabular}

Table 6. Gene diversity, number of alleles, allelic richness of the microsatellite markers detected from the Aconitum coreanum populations in Korea.

\begin{tabular}{|c|c|c|c|c|c|c|}
\hline \multirow{2}{*}{ Popn. } & \multicolumn{3}{|c|}{ AK_CA03 } & \multicolumn{3}{|c|}{ AK_CT07 } \\
\hline & gene diversity & \#alleles & allelic richness & gene diversity & \#alleles & allelic richness \\
\hline Seondol & 0.536 & 3 & 2.375 & 0.577 & 4 & 2.496 \\
\hline Donggang & 0.626 & 3 & 2.597 & 0.773 & 4 & 3.280 \\
\hline Hanbando & 0.577 & 3 & 2.523 & 0.637 & 3 & 2.651 \\
\hline Baeilchi & 0 & 1 & 1.000 & 0 & 1 & 1.000 \\
\hline Tongduduk & 0.200 & 2 & 1.600 & 0.400 & 3 & 2.200 \\
\hline Panun & 0.381 & 3 & 1.973 & 0.371 & 2 & 1.830 \\
\hline Gundungchi & 0.564 & 3 & 2.404 & 0.552 & 3 & 2.166 \\
\hline Daehwa & 0.261 & 3 & 1.744 & 0.614 & 3 & 2.573 \\
\hline Wondongjae & 0.714 & 3 & 2.851 & 0.631 & 3 & 2.622 \\
\hline Hongcheon & 0.429 & 2 & 1.930 & 0.667 & 3 & 2.809 \\
\hline Daeryongsan & 0.125 & 2 & 1.375 & 0 & 1 & 1.000 \\
\hline Hau & 0.100 & 2 & 0.130 & 0.100 & 2 & 1.300 \\
\hline Total & - & 4 & 2.482 & - & 5 & 2.689 \\
\hline
\end{tabular}

Table 7. Estimates of heterozygosity, $F$ statistics of the microsatellite marker loci detected from the Aconitum coreanum populations in Korea.

\begin{tabular}{cccccccccc}
\hline Locus & $H_{O}$ & $H_{E}$ & $F_{I S}$ & $F_{S T}$ & $F_{I T}$ & $D_{s t}$ & $D_{s t}{ }^{\prime}$ & $H_{T}{ }^{\prime}$ & $G_{s t}$ \\
\hline AK_CA03 & 0.401 & 0.585 & 0.079 & 0.275 & 0.332 & 0.196 & 0.214 & 0.595 & 0.340 \\
AK_CT07 & 0.250 & 0.615 & 0.500 & 0.205 & 0.603 & 0.128 & 0.140 & 0.594 & 0.220 \\
\hline Mean & 0.326 & 0.600 & 0.304 & 0.239 & 0.471 & 0.162 & 0.177 & 0.594 & 0.280 \\
\hline
\end{tabular}

$H_{O}$ : observed heterozygosity; $H_{E}$ : expected heterozygosity under $\mathrm{H}-\mathrm{W}$ equilibrium; $F_{I S}$ : inbreeding coefficient of an individual (I) relative to the subpopulation (S); $F_{S T}$ : the effect of subpopulations (S) compared to the total population (T); $F_{I T}$ : inbreeding coefficient of an individual (I) compared to the total population (T); $D_{s t}$ : amount of gene diversity among samples; $D_{s t}{ }^{\prime}$ : amount of gene diversity among samples, independent of the number of samples; $H_{T}{ }^{\prime}$ : overall gene diversity, independent of the number of samples; $G_{s i}$ an estimator of the parameter $F_{S T}$.

microsatellite markers, only two markers (AK_CT07 and AK_CA03) were polymorphic (Table 4). These two markers showed significant departure from HardyWeinberg equilibrium $(\mathrm{P}<0.05)$.

\section{Analysis of Genetic diversity using Microsatellite}

AK_CA03 microsatellite marker was successfully am- plified for the 142 individuals of $12 \mathrm{~A}$. coreanum populations, while AK_CT07 microsatellite marker was amplified for 132 samples (Table 5). Four alleles (235, 237, 239, $241 \mathrm{bp}$ fragments) and five alleles (170, 172, 174, 178, $180 \mathrm{bp}$ fragments) were detected for AK_CA03 and AK_ CT07 loci, respectively (Table 5). 237 bp fragment and $172 \mathrm{bp}$ fragment were the most common alleles for AK CA03 and AK_CT07 loci, respectively. 241 bp fragment 
Table 8. Population pairwise $F_{S T}{ }^{\prime}$ s estimated from the microsatellite markers of Aconitum coreanum populations in Korea.

\begin{tabular}{|c|c|c|c|c|c|c|c|c|c|c|c|c|}
\hline Popn. & SD & DG & $\mathrm{HB}$ & BI & TD & $\mathrm{PU}$ & GD & DH & WD & $\mathrm{HC}$ & DR & $\mathrm{HU}$ \\
\hline Seondol(SD) & 0.000 & & & & & & & & & & & \\
\hline Donggang (DG) & 0.016 & 0.000 & & & & & & & & & & \\
\hline Hanbando (HB) & -0.022 & -0.012 & 0.000 & & & & & & & & & \\
\hline Baeilchi(BI) & -0.037 & -0.083 & -0.070 & 0.000 & & & & & & & & \\
\hline Tongduduk(TD) & 0.040 & -0.072 & -0.011 & -0.024 & 0.000 & & & & & & & \\
\hline Panun (PU) & -0.028 & 0.018 & -0.024 & 0.002 & 0.111 & 0.000 & & & & & & \\
\hline Gundungchi(GD) & -0.023 & 0.024 & -0.019 & -0.022 & 0.060 & -0.030 & 0.000 & & & & & \\
\hline Daehwa(DH) & 0.059 & -0.037 & 0.014 & -0.061 & -0.069 & 0.110 & 0.081 & 0.000 & & & & \\
\hline Wondongjae(WD) & -0.049 & -0.027 & -0.052 & -0.084 & -0.025 & -0.054 & -0.049 & 0.014 & 0.000 & & & \\
\hline Hongcheon (HC) & -0.019 & 0.040 & 0.001 & 0.158 & 0.259 & -0.020 & -0.034 & 0.246 & -0.053 & 0.000 & & \\
\hline Daeryongsan (DR) & 0.513 & 0.448 & 0.535 & 0.911 & 0.874 & 0.642 & 0.491 & 0.815 & 0.433 & 0.600 & 0.000 & \\
\hline $\operatorname{Hau}(\mathrm{HU})$ & 0.599 & 0.529 & 0.620 & 0.938 & 0.909 & 0.721 & 0.582 & 0.857 & 0.540 & 0.705 & 0.055 & 0.000 \\
\hline
\end{tabular}

*Significant pairwise $F_{S T}$ values $(\mathrm{P}<0.01)$ are bold-faced.

Table 9. Hierarchical nested analysis of molecular variance(AMOVA).

\begin{tabular}{lrrrrrr}
\hline \multicolumn{1}{c}{ Source } & d.f. & S.S. & Variance & $\%$ Var & Statistics & P-value \\
\hline No grouping & & & & & & \\
$\quad$ Among populations & 11 & 116.556 & 0.39913 & 22.86 & $F_{S T}=0.229$ & $<0.0001$ \\
Within populations & 272 & 366.416 & 1.34712 & 77.14 & & \\
Total & 283 & 482.972 & 1.74624 & & & \\
\hline Regional grouping (Chuncheon vs. the other region) & & & & & \\
Among group & 1 & 103.504 & 1.62537 & 54.71 & $F_{G T}=0.547$ & 0.0235 \\
Among populations within groups & 10 & 13.052 & -0.00178 & -0.06 & $F_{P G}=-0.001$ & 0.5064 \\
Within populations & 272 & 366.416 & 1.34712 & 45.35 & $F_{P T}=0.547$ & $<0.0001$ \\
Total & 283 & 482.972 & 2.97070 & & & \\
\hline
\end{tabular}

of AK_CA03 locus was only detected from Hau population. $178 \mathrm{bp}$ and $180 \mathrm{bp}$ fragments of AK_CT07 locus were detected only from Donggang and Seondol population, respectively. In case of allelic richness, gene diversity, and the number of alleles, AK_CT07 locus showed higher statistics than AK_CA03 locus (Table 6). Generally, more than three alleles were detected from the populations bigger than population size of 10 individuals. Although Wondongjae population is small $(n=7)$, it shows highest allelic richness for AK_CA03 locus, while Donggang population show highest allelic richness for AK_CT07 locus. Geographically, populations in Chuncheon area, Daeryongsan and Hau populations, showed lower gene diversity and allelic richness than those in Youngwol, Hongcheon, and Pyeongchang. The expected heterozygosity under HWE was not much different from the values of the microsatellite test, but the observed heterozygosity was slightly larger for the population data (Table 7). The mean $F_{S T}$ was 0.239 and the number of migrants (after correction for size; $N_{m}$ ) was estimated as 1.12586 by GENEPOP. Population pairwise $F_{S T}$ 's presented significant geographic structure (Table 8). Two Chuncheon populations presented significantly large pairwiase $F_{S T}$ values with the rest of the populations (Table 8). Hierarchical nested analysis of molecular variance (AMOVA) was done to evaluate the geographic structure of genetic variation. Without regional grouping, $77.1 \%$ of variance was distributed within population and $22.9 \%$ among population, respectively (Table 9). When two Chuncheon populations were treated as separate group from the rest, $54.7 \%$ of variance was accounted for by among regional groups, although the $F$ statistic is not significant $(\mathrm{P}=0.0235)$. Still, $45.4 \%$ of variance was distributed within populations $(\mathrm{P}<0.0001)$. Among population variance was negligible with $\mathrm{P}=0.5064$.

\section{Discussion}

Both the two microsatellite loci discovered in this study significantly deviated from the Hardy-Weinberg equilibrium. The reason for the deviation may reside in the failure of amplification of marker due to the existence of variation at the $3^{\prime}$ terminal of the primers (Jarne and Lagoda, 1996; Dakin and Avise, 2004), over-representation of homozygote over heterozygote due to over-replication of specific alleles through competitive PCR (partial null), heterozygote deficit, presence of null allele, very small population size (An et al., 2010; Wang et al., 2011), or effect of natural selection and genetic structure of the population (Wahlund effect). Such null allele can mislead the results by making analyses of microsatellite com- 
plicated. Heterozygote deficit of $A$. coreanum may have been caused by small population size studied and/or excess of selfing over outcrossing due to the low density of $A$. coreanum in the field. As the density and population size of $A$. coreanum are generally small, this may have been a major cause for deviation from HWE. Also the lack of active seed dispersal mechanism for Aconitum may have reduced chance to exchange genetic material. Thus, once the size of population declines and fragmented, local populations of $A$. coreanum may easily undergo selfing and lose genetic variation.

Lack of sequence variation of the eight organellar markers amplified and sequenced in this study again confirms the results of Lim (2003) and Noh (2009) where A. coreanum showed lack of genetic variation while other tetraploid Aconitum species show polymorphisms and multiple sequence types. This strongly suggests that $A$. coreanum might have long been reproductively isolated from other tetraploid Aconitum species in Korea and/or maintained as a distinct evolutionary lineage. While $A$. coreanum is genetically distinct from other Aconitum, uniform sequence type of $A$. coreanum suggests that there has been continuous gene flow among them or it has dispersed relatively recently after speciation. The number of migrants $\left(N_{m}\right)$ and $F_{S T}$ values estimated from the microsatellite loci are relatively small $\left(N_{m}=1.12586 ; F_{S T}=\right.$ 0.205 and 0.275 ) and $77.1 \%$ of molecular variance are accounted for by within population variance. This indicates that there is not much genetic differentiation among A. coreanum populations in Korea. This fits with the idea that $A$. coreanum may have dispersed rapidly recently.

However, significant population pairwise $F_{S T}$ estimates of $A$. coreanum in Korea suggests that there exists evident geographic differentiation. This may have been caused by sampling artifact, though, since we have collected mainly around Youngwol, with extra two populations from Chuncheon, at least $60 \mathrm{~km}$ apart from Pyeongchang and Youngwol. The lack of significance of $F$ statistics in hierarchical nested AMOVA indicates that still the genetic variance are represented by within population variance. Wider and denser population sampling and increases in the sample size may reduce the effect of population differentiation. Further long-term monitoring and study on reproductive biology will help understand the genetic structure and dynamics of $A$. coreanum and will help conserve and recover natural populations.

\section{Acknowledgements}

This project was supported by a grant entitled "The Genetic Evaluation of Important Biological Resources (2011)" from the National Institute of Biological Resources. Authors thank Joo Hwan Kim and Chang Kun
Lim at Daegu University, Young-Chul Kim at Korea Botanic Garden for their help with DNA sampling and collection, and Wonju Regional Environmental Office for help with collection permit. Also, authors thank three anonymous reviewers for their insightful comments and suggestions.

\section{REFERENCES}

An, H.S., J.-h. Lee, J.K. Noh, H.C. Kim, C.J. Park, B.H. Min and J.-I. Myeong. 2010. Ten new microsatellite markers in cutlassfish Trichiurus lepturus derived from an enriched genomic library. Anim. Cells. Syst. 14:169-174.

Bessonova, I.A., M.S. Yunusov, V.G. Kondrat'ev and A.I. Shreter. 1987. Alkaloids of Aconitum coreanum. I. Structure of acorine. Chemistry of Natural Compounds 23:573575.

Bosch, M. and N.M. Waser. 1999. Effects of local density on pollination and reproduction in Delphinium nuttallianum and Aconitum columbianum (Ranunculaceae). Amer. J. Bot. 86:871-879.

Chung, K.-S., B. Nam, M.S. Park, J.A. Eom, B.-U. Oh and G.Y. Chung. 2011. Chromosome numbers of eight taxa of Aconitum L. in Korea and their systematic significance (Ranunculaceae). Korean. J. Pl. Taxon. 41:215-222.

Chung, M.G. and C.-W. Park. 2000. Notes on spatial genetic structure in a hybrid population between Aconitum japonicum subsp. napiforme and A. jaluense (Ranunculaceae). Ann. Bot. Fenn. 37:243-247.

Dakin, E.E. and J.C. Avise. 2004. Microsatellite null alleles in parentage analysis. Heredity 93:504-509.

Demesure, B., N. Sodzi and R.J. Petit. 1995. A set of universal primers for amplification of polymorphic non-coding regions of mitochondrial and chloroplast DNA in plants. Mol. Ecol. 4:129.131.

Dzhakhangirov, F.N. and I.A. Bessonova. 2002. Alkaloids of Aconitum coreanum. X. Curare-like activity-structure relationship. Chemistry of Natural Compounds 38:74-77.

Excoffier, L., G. Laval and S. Schneider. 2005. Arlequin ver. 3.0: An integrated software package for population genetics data analysis. Evolutionary Bioinformatics Online 1: 47-50.

Fazekas, A.J., K.S. Burgess, P.R. Kesanakurti, S.W. Graham, S.G. Newmaster, B.C. Husband, D.M. Percy, M. Hajibabaei and S.C. H. Barrett. 2008. Multiple multilocus DNA barcodes from the plastid genome discriminate plant species equally well. Public Library of Science ONE 3: e2802. doi:10.1371/journal.pone.0002802.

Glaubitz, J.C. 2004. CONVERT: a user friendly program to reformat diploid genotypic data for commonly used population genetic software packages. Molecular Ecology Notes 4:309-310.

Goudet, J. 2001. FSTAT, a program to estimate and test gene 
diversities and fixation indices (version 2.9.3). http:// www.unil.ch/izea/softwares/fstat.html.

Gupta, P.K., H.S. Balyan, P.C. Sharma, B. Ramesh. 1996. Microsatellites in plants: a new class of molecular markers. Curr. Sci. 70:45-54.

Hamilton, M.B., E.L. Pincus, A. Di Fiore and R.C. Fleischer. 1999. Universal linker and ligation procedures for construction of genomic DNA libraries enriched for microsatellites. BioTechniques 27:500-507.

Jarne, P. and P.J. LLagoda. 1996. Microsatellites, from molecules to populations and back. Trends Ecol. Evol. 11:424-429.

Jin, W., C. Chen, and E.B. Wang. 1998. A karyotaxonomical study on 6 species of Aconitum in Liaoning area. Bull. Bot. Res., Harbin 18:163-172 (in Chinese).

Kadota, Y. 1987. A revision of Aconitum subgenus Aconitum (Ranunculaceae) of East Asia. Sanwa Shoyaku, Utsunomiya.

Kalia, R.K., M.K. Rai, S. Kalia, R. Singh, and A.K. Dhawan. 2011. Microsatellite markers: An overview of the recent progress in plants. Euphytica 177:309-334.

Lee, H.-W., H.-R. Chung, T.-H. Roh, Y.-H. Kwon, C.-H. Kim, J.-O. Hyun and I.-S. Jang. 2005. Categorization and Conservation of the Threatened Plant Species in Environmental Impact Assessment. Korea Environment Institute (in Korean).

Lee, Y.N. 1967. Chromosome numbers of flowering plants in Korea. J. Korean Res. Inst. Ewha Women's Univ. 11: 455-478.

Li, L. and Y. Kadota. 2001. Aconitum. In: Flora of China Editorial Committee (eds.), Flora of China, vol. 6, Caryophyllaceae through Lardizabalaceae. Missouri Botanical Garden Press, Missouri. pp. 150-227.

Lim, C.E. 2003. Chloroplast DNA Sequence Variation of Aconitum L. subgenus Aconitum (Ranunculaceae) in Korea: Interspecific Relationships and Hybridization. Ph. D. thesis, Seoul National University, Seoul.

Liang, M., S. Li, B. Shen, J. Cai, C. Li, Z. Wang, X. Li, J. Gao, H. Huang, X. Zhang and J. Li. 2012. Anti-hepatocarcinoma effects of Aconitum coreanum polysaccharides. Carbohydrate Polymers 88:973-976.

Noh, T.-K. 2009. Hybridization in Aconitum subgenus Aconitum (Ranunculaceae) at Mt. Jiri in Korea. Ph.D. Dissertation. Seoul National University (in Korean).

Noh, T.-K. and C.-W. Park. 2000. ITS sequence variation of Korean Aconitum (Ranunculaceae) species. The 55th annual meeting of the Korean Association of Biological Sciences. P. 100 (in Korean).

Oh, S. and C.-W. Park. 1998. Crossability of the Aconitum jaluense species complex (Ranunculaceae) in Korea. Korean J. Biol. Sci. 2:435-438.

Park, C.W. 2007. Aconitum. In: Flora of Korea Editorial Committee (eds.), The Genera of Vascular Plants of
Korea. Academy Publishing Co., Seoul, Korea. pp. 176182.

Raymond M. and F. Rousset. 1995. GENEPOP (version 1.2): population genetics software for exact tests and ecumenicism. J. Heredity 86:248-249

Rozen, S. and H.J. Skaletsky. 1998. Primer 3. Code available at http://www.genome.wi.mit.edu/genome_software/ other/primer3.html.

Schuelke, M. 2000. An economic method for the fluorescent labeling of PCR fragments. Nat. Biotechnol. 18:233-234.

Shanker, A., A. Bhargava, R. Bajpai, S. Singh, S. Srivastava and V. Sharma. 2007. Bioinformatically mined simple sequence repeats in UniGene of Citrus sinensis. Sci Hortic-Amsterdam 113:353-361.

Swofford, D.L. 2003. PAUP*. Phylogenetic Analysis Using Parsimony (* and Other Methods). Version 4. Sinauer Associates, Sunderland, Massachusetts.

Taberlet, P., L. Gielly, G. Patou and J. Bouvet. 1991. Universal primers for amplification of three noncoding regions of chloroplast DNA. P1. Mol. Biol. 17:1105-1109.

Tang, Q.-Fa., W.-C. Ye, J.-H. Liu and C.-H. Yang. 2012. Three new hetisine-type diterpenoid alkaloids from Aconitum coreanum. Phytochemistry Letters 5:397-400.

Tehrani, M.S., M.M. Mardi, J. Sahebi, P. Catalan and A. Diaz-Perez. 2009. Genetic diversity and structure among Iranian tall fescue populations based on genomic-SSR and EST-SSR marker analysis. Plant. Syst. Evol. 282: 57-70.

Van Oosterhout, C., W.F. Hutchinson, D.P.M. Wills and P. Shipley. 2004 MICRO-CHECKER: software for identifying and correcting genotyping errors in microsatellite. Mol Ecol Notes 4:535-538

Wang, Y., F. Wang, Y.H. Shi, Z.F. Gu and A.M. Wang. 2011. Development and characterization of 60 microsatellite markers in the abalone Haliotis diversicolor. Genet. Mol. Res. 10:860-866.

Won, H. and S.S. Renner. 2005. The internal transcribed spacer of nuclear ribosomal DNA in the gymnosperm Gnetum. Mol. Phylogen. Evol. 36:581-597.

Won, H. 2009. Phylogenetic position of Corchoropsis Siebold \& Zucc. (Malvaceae s.1.) inferred from plastid DNA sequences. J. Plant Biol. 52:411-416.

Yu, J.-N., C. Won, J. Jun, Y. Lim and M. Kwak. 2011. Fast and cost-effective mining of microsatellite markers using NGS technology: An example of a Korean water deer Hydropotes inermis argyropus. PLoS ONE 6(11):e26933.

Zeng, L., T.-R. Kwon, X. Liu, C. Wilson, C.M. Grieve and G.B. Gregorio. 2004. Genetic diversity analyzed by microsatellite markers among rice (Oryza sativa L.) genotypes with different adaptations to saline soils. Plant Sci. 166:1275-1285.

Submitted: July 16, 2012, Accepted: August 24, 2012 